\title{
In Tempore Belli: Reflections on the Sense of the Universal in George Crumb’s Music of the Vietnam War*
}

\author{
Victor J. Rodriguez \\ University of Michigan-Shanghai Jiao Tong University Joint Institute, Shanghai, China \\ Ang-Cheng Kris Ho \\ Beijing Normal University-Hong Kong Baptist University United International College, Zhuhai, China
}

\begin{abstract}
This paper proposes new ways to understand the sense of universality in music through a reflection and analysis of George Crumb's Black Angels (Images I): Thirteen Images from the Dark Land, one of the defining musical expressions of the Vietnam War era. It centers on an analysis of the relationship of the body/self to an "ecology of war” produced through Crumb’s music that renders these selves indistinct within this musical geography. The selves that inhabit Black Angels could be that of anybody in particular since Crumb seeks to invoke in his music the primeval experience of terror that inhabits in all of us as the inheritors of mankind's violence. This sense of the universal militates against the desirable qualities of popular music that rely on the production of autonomous and singular selves that make the distinction between enemy and friend possible and distinct. We focus on Crumb's use of archaisms, his construction of time in this piece, and the author's overall purpose to invoke a time of war rather than to reflect the conditions of war, in order to delineate the contours of the universal time and space producing the undifferentiated primeval self of war. We conclude that although Crumb's rejection of the national self deprives the piece of a salient place in the popular cannon of the war, it has left an intellectual legacy on the times of the Vietnam War that deserves to be preserved.
\end{abstract}

Keywords: Crumb, Black Angels, Vietnam, war, universal, experimental music

\section{Introduction}

What does it mean for a category of knowledge or a narrative to be universal? And once a cultural production carries such connotation, are its assumptions and implied meanings normative upon other forms of life expressions? In this essay, we examine the qualities of the "universal" that permeates the production and dissemination of George Crumb's quartet Black Angels as it speaks in particular to the memory of the Vietnam war, and in general, to a human and universal experience of war. We examine how the formal qualities of Crumb’s music create the stage for the universal experience of war through the creation of an ecological space as

\footnotetext{
* Acknowledgements: The authors would like to acknowledge the generous assistance of United International College without which this research would not have been made possible.

Victor J. Rodriguez, Assistant Professor, University of Michigan-Shanghai Jiao Tong University Joint Institute.

Ang-Cheng Kris Ho, Assistant Professor, Beijing Normal University-Hong Kong Baptist University United International College.
} 
the theater of war. We analyze continuities made possible by Crumb's techniques between author and music, musical score and performance, author and performer, and performer and audience all which serve to subordinate the autonomy of self to the cosmic experience of fear and hope which the music seeks to make present in the music and its performance. We conclude with a brief examination of the reception of Crumb's Black Angels, its limited use in popular culture, and a comparison with the nation-bound music of the Vietnam War. Finally, we trace future avenues of investigation on Crumb's music and American culture in general specifically as to how the meaning of the political in American culture in general obscures the political implication of Crumb's music.

\section{Crumb’s Music and the Self}

George Crumb wrote Black Angels (Images I): Thirteen Images from the Dark Land as a work commissioned by the University of Michigan. The Stanley Quartet first performed it on October 23, 1970 in Ann Arbor, Michigan. Although the reception of Crumb's music in general has generated contradictory responses, most scholars have found in Black Angels a wondrous music appealing to the highest qualities of the human soul, one possessing "magical qualities" as Ofer Ben-Amots remarks (Bruns, Ben-Amots, \& Grade, 2005, p. v.) or offering a "transcendental view of the world" (Mac Lean, 1986, p. 20). The piece also seemed to embody a quintessentially American ethos with Crumb's music marking an "unprecedented phase in America's music" (Chase, 1986, p. 2). The piece certainly seemed to incorporate popular sentiment on the Vietnam War. Crumb himself echoed that perception on the historical salience of Black Angels piece. "Black Angels", he claimed, "was conceived as a kind of parable on our troubled contemporary world...the work portrays a voyage of the soul” (Crumb, 1990). Thus Black Angels embodied two overlapping yet contrasting qualities: a sense of universality — this was music that spoke to humanity and the human soul—and a deep sense of the local—it spoke to the American soul in tempore belli (in times of war) as Crumb himself notated on his score (Crumb, 1970). The tension between these two contrasting dimensions of Black Angels explains in great part why it eventually never shared an important place in the popular canon of the music of the Vietnam War.

Regardless of the critical consensus on Crumb's Black Angels as one of the defining musical expressions against the Vietnam War, this amplified string quartet has been almost forgotten in American music history except for select musical circles devoted to the academic study of the American avant-garde in particular and 20th century classical music in general. If Crumb's quartet possessed such luminous qualities and represented so much of the American ethos of that time, why has it receded in the imagination of the concert-going public at large? Why has it not reached the canonical status of other music on the Vietnam War, whether popular or classical? Why would a piece written by an author so much in love with his nation-his fond recollections of his Appalachian boyhood are a case in point (Cohen, 2002; Dwyer \& Crumb, interview, 2014; Shuffett \& Crumb, interview, 1986; Gillespie, 1986)—not receive the same recognition accorded to Bruce Springsteen's music, for example?

Part of the answer lies in how Black Angels connects to the collective memory of the war. As we have argued previously, Crumb's music indeed subverted "the conventions of popular memory" (Ho \& Rodriguez, 2012, p. 202), more specifically the memory of the only war the United States has lost, a status that has secured for it "an ironic place in American music: both a quintessentially American response to the war and one that is for 
the most part absent from the musical memory of Americans” (Ho \& Rodriguez, 2012, p. 202). The subversive qualities of Crumb's piece speak to the strict separation between the American and the foreign "other" that structured the popular memory of the war in American music. Black Angels unsettled such binaries and instead allowed the listening self to transit the fluid boundaries that connect enemy and friend (Ho \& Rodriguez, 2012). We now wish to go beyond that analysis and posit that the universal qualities of Black Angels rely on the construction of a music space invoking a cosmic experience of war shared by all humans. Such universal experience of war negates in principle the primacy of the binaries that inform nationalist memories of war; they cannot be sustained in such conception of music. Thus, we move our investigation of Black Angels to the way Crumb's piece imbricates the self musically in the cosmos. We are concerned with how in Crumb's music the boundaries of the self become porous to the extent that the American (standing in for the western world) and the Vietnamese (standing in for the "East") become indistinguishable. How does his music establish such permeability not only in the listener's perception of the music, but also extend it the haunting selves that transit the terrain of war traced in the musical score? How are these continuities achieved and how are autonomous selves subordinated to the larger experience of war?

Our writing speaks to the salience of two important relationships in music (as well as in all forms of cultural production): that between the body/self and identity and another one between the body/self and the nation. As Hebdige has argued, the body constitutes a site of resistance and a location for the affirmation of identity (Hebdige, 1979; as cited in Beard, 2004). Thus, it signifies a form of separation. This idea of the body/self finds itself intimately tied to how we conceive our relationship to the nation. In Benedict Anderson's celebrated definition of the nation as an "imagined community", each individual self relates to the national body as a factor of his or her experience as lived within a national body conceived as limited in its temporal and geographical boundaries (Anderson, 1990). Given such conception of the nationalist self, each citizen qua citizen understands him/herself as also bounded by his/her body and the body of the nation to which it relates. The centrality of the autonomous and distinct body to the nationalist imagination is central to our investigation given our contention that Crumb's music's reach for the universal disregards such forms of autonomy and thus conspires against the qualities that make nationalist music so popular in the collective imagination. Thus, we argue that Crumb's music speaks not a sense of universality manifest in the nation-state and its categories of identity but to universal qualities based on the love of nation rooted in Crumb's understanding of the experience of men throughout the ages. In Black Angels, that universal experience centers on the invocation of a primeval ecology of war, which responds to a generalized experience of violence in the human race. That universality does not deny but seeks to speak directly to America's involvement in the Vietnam War.

\section{The Universal: The Primeval Ecology of War}

In Black Angels, Crumb seeks to recall a primeval experience of war. He does not intend to reflect war in the conventional sense, but to make music the embodiment of the times of war and thus to make Vietnam's tempori belli a constitutive part of that experience. In doing so, Crumb’s Black Angels assumes, as Victoria Adamenko convincingly argues, mythic qualities (2005). These mythic qualities structure a space within which the experience of war is invoked. The actuality of the space produced through the making of the music and made present in the score and through its performance, lead us to speak about a Black Angel's primeval ecology 
of war. In Black Angels, Crumb thus invokes a primitive (perhaps pre-historic) space for war which all of us share as part of our human condition (Adamenko, 2007). ${ }^{1}$ It creates musically a space for us to inhabit and share in the present the times of war: thus its universality.

These mythic qualities have been well studied by scholars and are produced mostly if not entirely by Crumb's use of numerology, cyclicality, syncretism, and archaisms, many of which become, in Adamenko's words, “mythologems" (2005, 2007). Let's take the first of these mythologems: numerology. Crumb employed numbers-more specifically in this piece the number 7 and 13-to structure Black Angels and convey associations with the spirit world. Crumb desires to summon the times when numbers were understood as having inherent properties that could be manipulated to control nature. A clear example is the use of the tritone and its correspondence with the number 7 , which exemplifies the use of numbers conceived as entities that possess meanings independent of the user (see Figure 1). We could also look at the concept of cyclical time in the piece. Just as numbers, cyclical time takes us back to archaic (yet not invalid) understandings of the meaning of time. Cyclicality refers to the property of time as recurrent and thus not conceived as infinitely linear and progressive. Most of the syncretic qualities of Black Angels, that is Crumb's integration of a plurality of motifs, musical genres, and extended vocal techniques into the fabric of the composition, themselves recur during the piece as a form of meaning-making technique that relies on a concept of time prior to the contemporary notion of progress. We also could make references to Crumb's use of archaisms both in the form of ancient symbols (such as the circle) as well as in the invocation of the "sounds of nature" for which this piece is famous. One example of the latter would be the section of the insect drones, which Crumb specifically refers to as the "primeval sounds" of "prehistoric music" (as cited in Adameno, 2007).

Yet, how does the recourse to these mythic constructs structure such specific ancient space of war in Black Angels? They do so in various ways. One of them is by creating an atmosphere of timelessness. Crumb is invoking an experience deemed common to all of humankind. Crumb’s “electric insects”, for example, speak to our common relation to nature as the originator of our perception of music. The sound of insects recalls the primordial "ancient, pre-historic music" of humankind through the use of extended vocal techniques as players shout, chant, whistle, whisper, or play gongs, maracas, and crystal glasses to create the natural environment of ancient men. Black Angels seeks to establish continuity with the "sounds of nature". It seeks to place us within the ecology of darkness and fear but also of light and hope that suffuses our ancestral history of violence.

Crumb also employs the circle as a mythic symbol in his use of graphic notation as well as in the very arrangement on stage of the musicians and in the recurring motifs of the score in order to employ circularity and cyclicality to denote the perception of time of ancient man (see Figure 2). The attribution of inherent qualities to numbers, which invokes magic as a way to perceive, to understand, and manipulate nature, similarly summons the atmosphere of ancient man (see Figure 3). The instruction to performers to shout a series of numbers from 1 to 10 in various languages (such as Spanish and Japanese as illustratred in Figure 4) seeks to recall the effort of our ancestors to control our environment through the inherent power of numbers. Indeed, Crumb calls back historical times deemed today as "superstitious" or "magical” (as opposed to scientific and

\footnotetext{
${ }^{1}$ In her book Neo-Mythologism in Music, Adamenko argues that Jung could have been an important influence in Crumb's relation to the archaic. Certainly, Crumb's awareness of Jung's notion of the "collective unconscious" strengthens the case for Crumb’s construction of a primeval experience of war. See Adamenko (2007).
} 
modern). Crumb's own interpretation of his work suggests strongly that he believes that these experiences have not disappeared but dwell within our psyche. In fact one could venture and argue that the power of his music relies not in summoning the national community in times of war, but another community conceived as sharing a primeval experience of war still present deep within each of us. In this sense, we can speak of Black Angels as embodying a universal spirit, one that is not defined against a certain enemy or "other" but that is crafted through the musical fabric of the universal community of man.

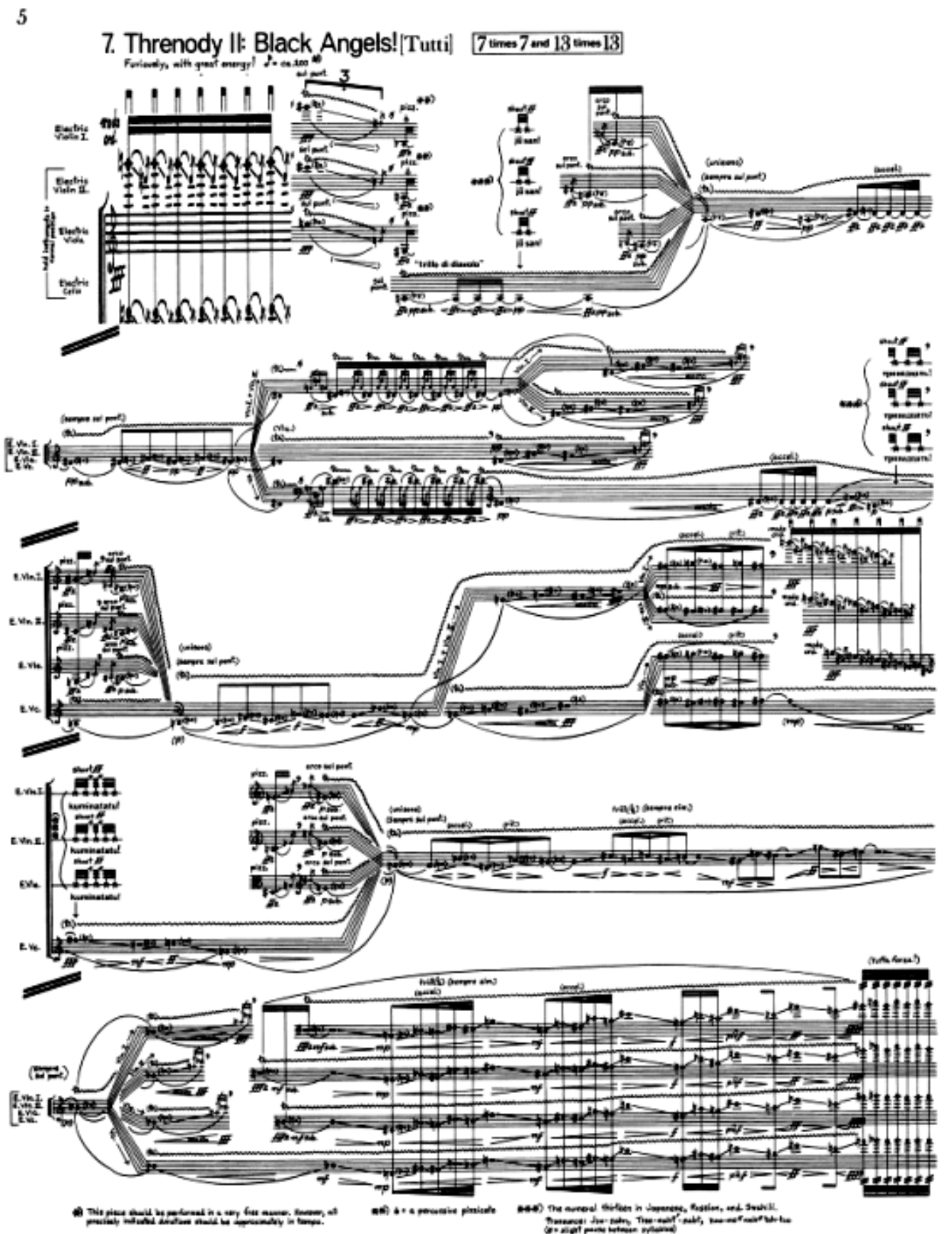

Fogure 1. An example of the use of the tritone from Black Angels: 7. Threnody II: Black Angels! [Tutti], 7 times 7 and 13 times 13. (c1971 C. F. Peters Corporation. All rights reserved. Used by permission. 
5

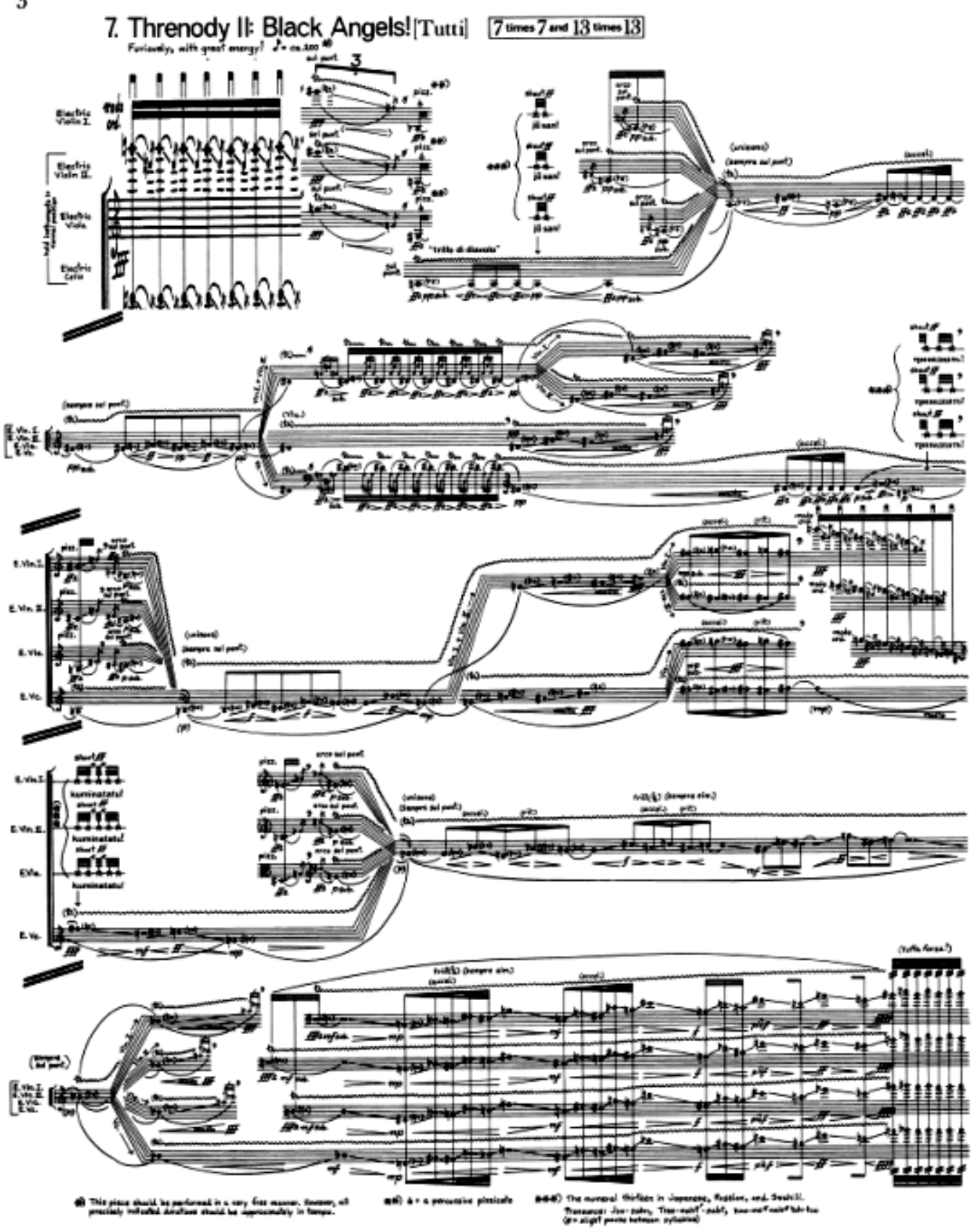

Figure 2. An example of circular notation from Black Angels: 7. Threnody II: Black Angels! [Tutti], 7 times 7 and 13 times 13. The integration of several other forms of archaisms such as the use of numbers as property-carrying entities may also be seen here. (C1971 C. F. Peters Corporation. All rights reserved. Used by permission.

Therefore this is not the ancient man of social science, which can be recreated through the scientific study of his remains. This is not the abstract ancient man of the archaeologist or the anthropologist, deemed to exist in a time different from ours (Fabien, 2002). This is not the ancient man of the historicist who understands his time as inaccessible to our experience. This is an ancient man to be invoked through this music as our ancestor. He is made present through a music that speaks his language and knows his world. 
10. God-music [Solo: Aria accompagnata]

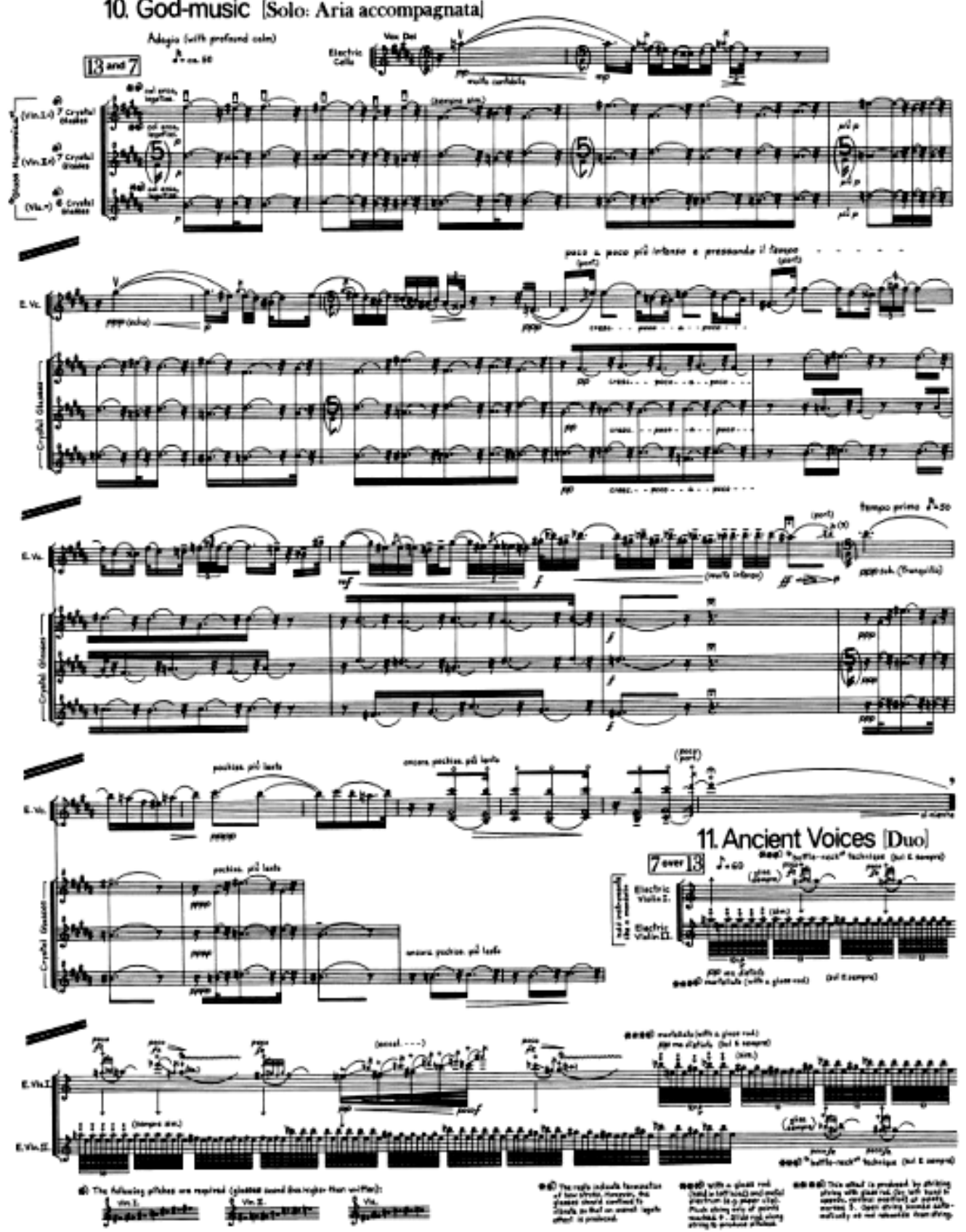

Figure 3. An example of pre-modern concept of numbers as invested with physical properties from Black Angels: 10 God-Music [Solo: Aria accompagnata]. (c) 1971 C. F. Peters Corporation. All rights reserved. Used by permission.

In invoking a time understood as fundamentally universal and still permeating our present experience of time, Black Angels speaks to the historical moment before humans rationalize their lives in social worlds. This sense of the universal explains Crumb's project to summon in Black Angels an ancient self he deems to be "pre-analytical". Here the composer finds the most effective use of archaisms that signal the historical moment that Crumb specifically seeks to make present for us. Crumb's "turn to the pre-reflective" (Adamenko, 2005) 
intends to produce aspects of the pre-analytical experience of men when pure experience, rather than abstraction, structured our responses to our habitat and to our others. Crumb does not believe that the affective states tied to this temporality have necessarily disappeared, but they rather still belong to our responses to our current social conditions. It constitutes our universal inheritance.
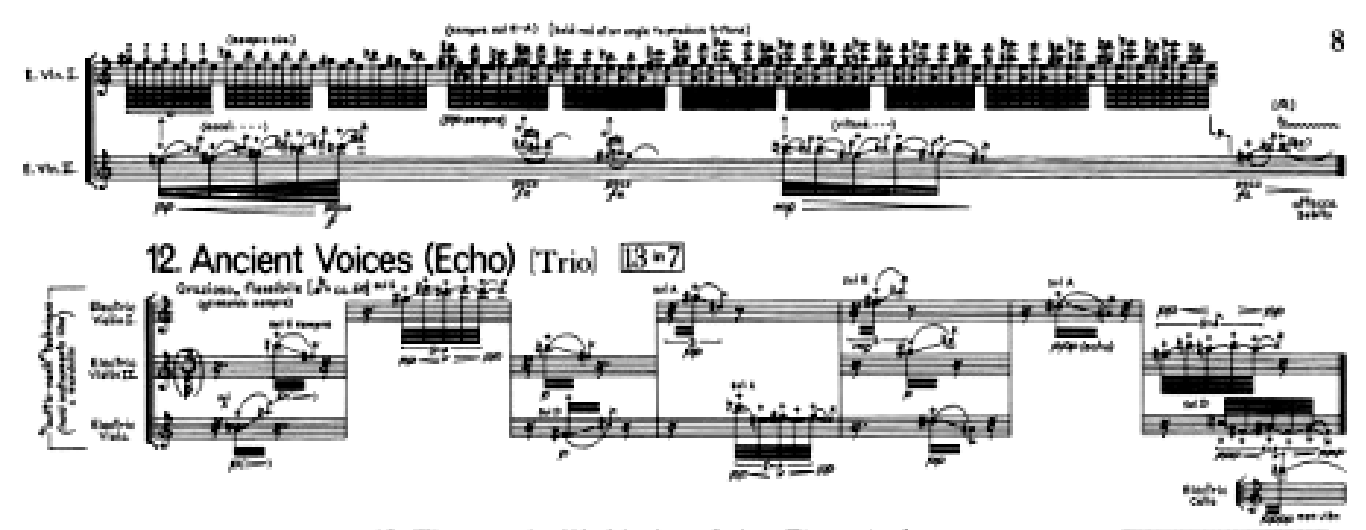

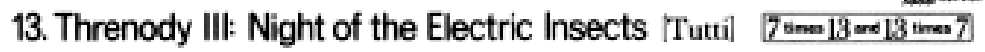

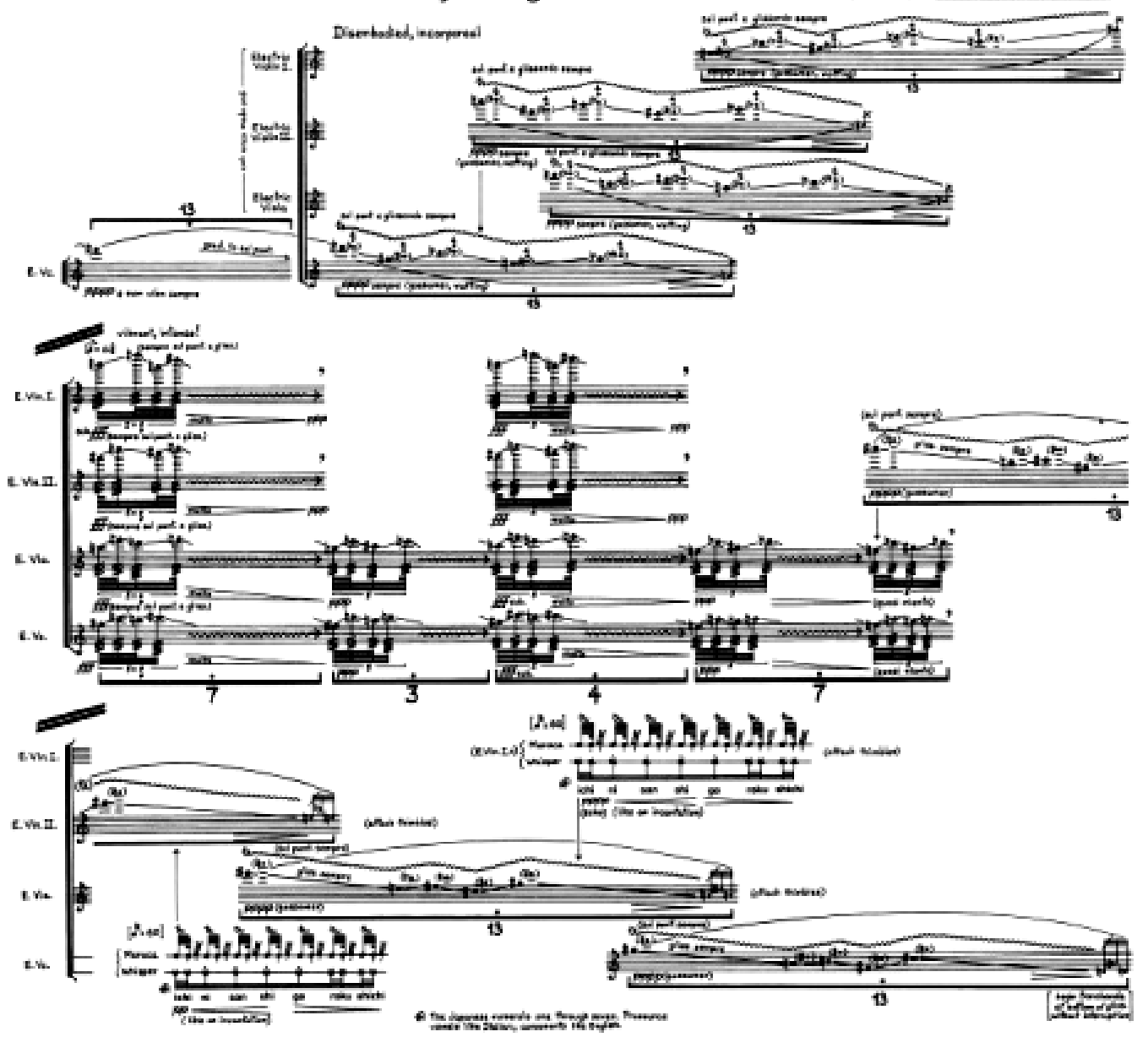

Figure 4. An example of Japanese numerals from 13 Threnody III: Night of the Electric Insects [Tutti] 7 times 13 and 13 times 7. ( ) 1971 C. F. Peters Corporation. All rights reserved. Used by permission. 
Categorizing experience along the binaries of the "analytical/pre-analytical" could potentially be seen as problematic. After all, apologists for colonialism defended empire through the affirmation of western cognitive superiority and the categorization of the colonized as living in a pre-cognitive dimension of historical experience, which only the west could understand, give form and thus explain and appropriate. We can speak similarly of how the defense of slavery in Crumb's own America found support in great part in the belief of the absolute cognitive superiority of western men over African slaves. This superiority spoke to the unique ability of the western man for abstraction (Blaut, 1993). Is Crumb colonizing our past rather than affirming it as our common inheritance? It does not seem so. Crumb's musical use of myth and the world created with, for, and through the music at the very least challenges the colonial vision that informed the binaries that served as foundation of imperial domination. The composer's invocation of mythical time stands in contraposition to the conventions of linear time that characterizes western conceptions of history and which served as foundation for western colonialism and its form of historical memory. Black Angels' music notation, performance, and reception similarly challenge the conventional narrative structures that infused ideologies of western supremacy. Thus Crumb's music should not be considered an appropriation of the human past purely for present-day concerns.

If we take a look at Black Angels' extensive use of non-tonal music, we can realize how far Crumb has gone in moving away from such western assumptions of superiority. Timothy D. Taylor has connected the rise of tonal music to western music qua western where Europe defined its sense of identity vis-à-vis its primitive others. Tonality in music allowed western societies to develop an understanding of their selves as different from a primitive other, as was the case of the societies of the New World or distinct from the societies of what was denominated the "Orient". "Conceptions of selfhood", argues Taylor, were "intertwined with the origins of tonality” (Taylor, 2007, p. 10). It signified the centrality of Europe to world history. Taylor adds that, "tonality arose to a long supremacy in western European music in part because it facilitated a concept of spacialization in music that provided for centers and margins, both geographically and psychologically” (Taylor, 2007, p. 25) and “Tonality also signified teleology" (Taylor, 2007, p. 28). Yet, the key to Black Angels sense of the universal resides in the subordination of tonal music to the atonal qualities of the piece in general, not to its erasure. Crumb's does not intend to write non-western music, but to integrate the "west" into its overall project of summoning the ancient and thus "provincialized".

\section{The Local: The Vietnam War}

Thus Crumb has evoked for us the world of ancient man/woman as it dwells in us and has located the war within his/her milieu. It is in this aspect that one can posit the universality of his music. Yet, in doing so, he has erased crucial distinctions that undergird popular memory of the Vietnam War, especially the memory inscribed in the production of popular music that challenged the legitimacy of the war and the treatment of its soldiers. The universal aspects of the theatre of war invoked through Black Angels fosters a sense self similar to what Jacques Derrida denominates "undecidedness": In our case, the selves of enemy and friend are constantly dissolved and remade, a form of fluidity antagonistic to nationalist memory so invested in the clear distinction

\footnotetext{
${ }^{2}$ I am using the term here as an explicit reference to the Dipesh Chakrabarty's use of the term in his book Provincializing Europe. See Chakrabarty (2007).
} 
between selves, especially those between enemy and friend (Derrida, 1976). In resisting if not outright challenging the narrative time of the nation and its memorialization of the war, Black Angels refuses to rely in the sacrosanct identities of national memory. As Taylor argument implies, the social construction of national self in conventional tonal western music (its separateness from its "other", its circulation in linear time, and its location in a national space that is bounded, autonomous, and firmly located in a geography with clear centers and peripheries) becomes impossible in Black Angels (Taylor, 2007). The self, made present in Black Angels, does not stand for any national subject.

This may seem to contradict Crumb’s avowed references to the Vietnam War as the crucial referent for his inspiration in writing this piece. According to Crumb,

Very soon after I got into the sketching process, I became aware that the musical ideas were picking up vibrations from the surrounding world, which was the world of the Vietnam time. And there were dark currents operating and those things were somehow finding their way into the conception of the string quartet. (Oteri \& Crumb, interview, 2002)

He has also stated that,

As I got into the composition I realised it was pulling in more and more of the kind of hysteria...the hysteria that was reigning in the States in this period. It was a rather dark time. So much so, that at the end there, when I finished, I borrowed the Haydn, 'In time of war' and put that in the piece as a subscript. I just became aware of that but the intention wasn't there from the beginning. (Oteri \& Crumb, interview, 2002)

These observations by Crumb speak to the qualities of his compositional philosophy in two important ways. First, Crumb affirms the local/national aspects of the piece: It speaks to the times of war during the Vietnam era in the United States. Second, it reflects Crumb's apprehension of time: How a pre-reflective moment (the writing of the music) yields to a cognitive moment where the appreciation of the qualities of the music already produced become visible and once they become visible they may be fully realized.

Thus, Crumb's statement confirms the particular relationship of Black Angels to Vietnam, while revealing at the same time what the dynamics of the pre-cognitive and the cognitive actually mean to him personally, providing solid clues to how he employed these categories in Black Angels. These binaries constitute dimensions of life, in this case of the artistic process (or of any form of human cultural production) whereby a pre-analytical moment is apprehended and made present (Adamenko, 2005). Thus the times of ancient man are actually dimensions of our very own present made available (made present) to us by the music, a music that affirms its stake on the present, a present lived by all of us in a time of war. We can now understand why Crumb would affirm that his piece was not political (Dwyer \& Crumb, interview, 2014). It is not political in the formal sense of institutions, laws, and particular forms of citizenship. The particular in Black Angels is tied to a different form of universality: not the universality of the nation-state as the only acceptable form of human community, but to the universality of the cumulative experience of humankind, in this particular case the universal experience of war, of loss, of fear, of horror, of death.

The self that is made present in Black Angels could be that of any soldier lost in the jungles of Vietnam, Vietnamese or American, listening in the darkness of countless fields and villages to the sounds of insects suddenly interrupted by the (un)expected presence of the other (or the opposite: How the presence of the other is 
interrupted by the sounds of nature). ${ }^{3}$ Our listening self is thrust into this landscape of horror and fear, sharing and yet refusing to share, such experience of loss and terror. It is within this landscape produced by Crumb's "universals of sounds", as in for example the section called Night of the Electric Insects that the full impact of Black Angels becomes evident: We share our collective memory of war; within that memory all selves are anonymous. The reception of Crumb's Black Angels testifies the purpose of Crumb's music, to the affective states that characterize the sense of the universal that permeates Black Angels, and to the qualities of the musical self that it sustains. Marcel Cobussen has related how listening to Crumb's quartet has yielded a fascination "beyond rationality, controllability, measurability. An encounter with music beyond the worlds that frame, name, and contain it as music. A relationship with music beyond theories, methods, and categories” (Cobussen, 2007, p. 3). As such, the self cannot be simply the object of artistic representation. Cobussen writes that "the subject of Black Angels is that which can never be the subject of composing, of music, but whose reality can be conjured up, and in that sense, made present: presented, instead of represented" (Cobussen, 2007, p. 16). Within the musical geography of Black Angels, the ancient human experience of our selves becomes possible once again. Yes, we are in Vietnam, but this is the "Vietnam" that belongs to humankind's experience of war; it is not a nationalist category. In this universal "Vietnam", the "fundamental violence" that forms the core of human experience becomes present (Cobussen, 2007, p. 190).

It is impossible to ignore some of the ironies that suffuse the qualities of the universal in Black Angels. One of the distinguishing characteristics of the narrative of the Vietnam War in American film and literature corresponds to the sense of terror produced by the inability of the American to identify the enemy, to locate the other within the human landscape of Vietnam. In a guerrilla war where the enemy would not fight in conformity to traditional conventions of war and where any villager could have been conceivably an enemy, violence ensued in proportion to the terror and anxiety of misidentification. A war between racialized nationals demanded distinct racialized and marked bodies. This is precisely what popular music provided to the memory of Vietnam: the autonomous racialized body of the American. Popular musical memory rejected all forms of misrecognition, even those within the boundaries of the nation. Buttressed by popular music's use of the tonal tradition, the popular memory of the Vietnam War relied on the clear distinctions between the American and the other. Filmic forms of cultural production, whether defending the war-as for example in the film The Green Berets—or condemning the war-as in Platoon — drew strict boundaries to delineate selves, bodies, identities, whether they are western or Asian, white American or Vietnamese, enemy or friend, ourselves and the other.

We must add to that how the cultural production in the post-war era similarly erased the body of the Vietnamese from an identifiable location within the national body (Martini, 2007). If any, as was the case with Bruce Springsteen's Brothers Under the Bridge for example, the music of the Vietnam War, especially that one dedicated to the Vietnam veteran, pleaded for a full affirmation of the place of the American military self within the body of the nation. Springsteen's song affirms the "I" of the American self: "I come home in '72/You were just a beautiful light” (Springsteen, 1983). It also marks the geography of Vietnam with the well-known markers of American consumer culture: "Saigon, it was all gone/The same Coke machines / As the

\footnotetext{
${ }^{3}$ Cobussen has noted that interruption in Black Angels contributes to a "fragmentarism" or "interruptism" that serves to articulate “extreme experiences” where the language employed cannot "surpass its object”. This means that the subject of Crumb's piece cannot be the subject of the music: It is simply invoked, made present. See Cobussen 2007.
} 
streets I grew on” (Springsteen, 1983). The song seeks recognition of the veteran within its own society: of the American in America and of the American experience in Vietnam qua American experience. The same qualities as those found in Brothers Under the Bridge permeate the plot of the Rambo films. Rambo's national origins, firmly planted in the American land, and contained by the technological power of American weaponry, provide Rambo with the necessary unity of self to confront the "other". One could even argue that the Rambo films precisely intend to do that: to restore an intact American self to a war experience that had seemingly erased national subjectivities at critical moments. Similarly, one could argue the same for Creedence Clearwater Revival's Fortunate Son or the Charlie Daniel Band's Still in Saigon, just to name a few, all of them musical pieces firmly located within the structural forms of western music and its meaning-making conventions and committed to a politics of recognition that privileges a national "I". As we have argued previously, the popular memory of the Vietnam War cannot rely on such confusions of self, on such expressions of universal experience, especially given the racial histories that impinge on the representation of the Asian other in American culture. There is no such psychic and corporeal solace in Black Angels.

One should then not be surprised that the only use of Black Angels within the corpus of popular American culture occurs in the film The Exorcist. The central thematic of the film centers on the corporeal confusions that ensue after the body of a typical American suburban child gets possessed by the spirit of the devil. The child's profane use of sacred symbols in sexual activity complicated even more the distinct qualities of the national body represented by the middle-class child at the center of the film's narrative. The film's narrative source in William Peter Blatty's novel of the same title evokes the times of the Vietnam War and the fear that ran through the American collective psyche as the war split American society apart. These fears-about the secret operations of the government, about the identity of the enemy—similarly reflected a political and cultural universe where the distinctions between friend and enemy hunted the American imagination. Was the enemy within the national body? Or was it outside the nation? This single use of Black Angels in film may be compared with the wider use of classical music in the popular Vietnam film. In Platoon, for example, the use of Barber's Adagio for Strings exemplifies the manifest qualities that tonal music provide to the popular narrative of the war and that makes it a far more popular choice (Howard, 2007).

\section{Conclusion}

Crumb's music extricates itself from the American historical imagination to the extent that it prioritizes a universal nexus between humans and the violence of war. In this domain of the abstract, the nationalist self evaporates. In the anonymity of war, we become equal. What we denominate as universal here is not so much the abstract soldier, but the very experience of war, which is distilled to the most visceral of experiences: the drone of insects, the sudden whisper, and the thunderous and violent sounds of the dark. We face here a different kind of universality; not the universality of reason, but the universality of the experience of war embodied in the pre-reflective experience of men and women, in the visceral feeling of terror. It is more than ironic, that a war whose cruelty and barbarism was intensified precisely by the inability of the American soldier to distinguish enemy and friend, would find in this piece a conduit to express such terror. Black Angels refuses to speak for anybody in particular. It rejects the conventions of popular memory. Crumb's music does not offer such comforts. 


\section{References}

Adamenko, V. (2007). Neo-Mythologism in music: From Scriabin and Schoenberg to Schnittke and Crumb. Hillsdale, NY: Pendragon Press.

Adamenko, V. (Autumn 2005). George Crumb’s channels of mythification. American Music, 23 (3), 324-354.

Anderson, B. (1990). Imagined communities: Reflections on the origins and spread of nationalism. London: Verso.

Beard, C., \& Gloag, K. (2004). Musicology: The key concepts. Oxford \& New York: Routledge.

Blaut, J. M. (1993). The colonizer's model of the world: Geographical diffusionsim and eurocentric history. New York: The Guilford Press.

Bruns. S., Ben-Amots, O., \& Grace, M. D. (Eds.). (2005). George Crumb \& The alchemy of sound: Essays on his music. Colorado Springs: Colorado College Music Press.

Chakrabarty, D. (2007). Provincializing Europe: Postcolonial thought and historical difference. New Jersey: Princeton University Press.

Chase, G. (1986). George Crumb: Portraits and patterns. George Crumb: Profile of a composer. D. Gillespie, (compiler and Ed.). New York: C. F. Peters Corporation.

Cobussen, M. (Spring 2007). Music and spirituality: 13 meditations around George Crumb’s black angels. The New Centennial Review, 7 (1), 181-211.

Cohen, D. (2002). Biography. George Crumb: A bio-bibliography. Westport: Greenwood Publishing Group.

Crawford, R. (2001). America's musical life: A history. New York: W.W. Norton \& Company.

Crumb, G. (1990). [Liner notes]. In Black angels: Thirteen images from the dark land [Recorded by the Kronos Quartet]. On Black angels [CD]. New York: Nonesuch Records.

Crumb. G. (1970). Black angels for electric string quartet. New York: C. F. Peters.

Crumb. G. (1980). Black angels: Thirteen images from the dark land [Recorded by the Kronos Quartet]. On Black angels [CD]. New York: Nonesuch Records.

Derrida, J. (1976). Of grammatology. (G. Spivak, Trans.). Baltimore: John Hopkins University Press.

Dwyer, B. [Interviewer]. Crumb, G. [Interviewee] (2014, January 24). Interview with Benjamin Dwyer. Retrieved from http://bejamindwyer.com

Fabien, J. (2002). Time and the other: How anthropology makes its object. New York: Columbia University Press.

Gillespie, D. (1986). George Crumb: A personal recollection. George Crumb: Profile of a composer. D. Gillespie, (Compiler and Ed). New York: C. F. Peters Corporation

Hebdige, D. (1979). Subculture: The meaning of style. New York: Routledge.

Ho, Ang-Cheng K., \& Rodriguez, V. J. (2012) Music and the politics of war: George Crumb’s 'black angels’ and the Vietnam war. In D. CHEN (Ed.), Knowledge, culture, and society. Singapore: IACSIT Press.

Howard, L. (Spring 2007). The popular reception of Samuel Barber's adagio for strings. American Music, 25 (1), 50-80.

Mac Lean, S. (1986). George Crumb, American composer and visionary. George Crumb: Profile of a composer. D. Gillespie, (Compiler and Ed.). New York: C. F. Peters Corporation.

Martini, E. A. (2007). Invisible enemies: The American war on Vietnam, 1975-2000. Amherst: University of Massachusetts Press.

Oteri, F.J., [Interviewer]. Crumb, G. [Interviewee]. (2002). Interview with Frank J. Oteri. Jumping off the page to become sound: Frank J. Oteri in conversation with George Crumb at his home in media, PA. Retrieved 2014, January 24 from http://NewMusicBox.org

Shuffett, R. [Interviewer]. Crumb, G. [Interviewee]. (1986). Interview with Robert Shuffett. George Crumb: Profile of a composer. D. Gillespie, (compiler and Ed.). New York: C. F. Peters Corporation.

Springsteen, B. (1983). Brothers under the bridge. On Tracks [CD]. New York: Columbia. (1998).

Steinitz, R. (October 1978). George Crumb. The Musical Times, 119 (1628), 844-845, 847.

Taylor, T. D. (2007). Beyond exoticism: Western music and the world. Durham: Duke University Press. 